\title{
A ética do intelecto: entrevista com Lúcia Santaella
}

\author{
Alexandre Rocha da Silva \\ Doutor; Universidade Federal do Rio Grande do Sul , Porto Alegre, RS, Brasil \\ arsrocha@gmail.com
}

\section{Resumo}

Nesta entrevista, Lúcia Santaella nos desafia a pensar sobre as potencialidades da semiótica em suas interfaces com a comunicação, o design, as tecnologias da inteligência, e também com a biologia, a geologia, a geometria em perspectiva interdisciplinar. Avalia algumas de suas principais obras e reconhece o vínculo existente entre semiótica e política, por ela explorado de maneira transversal desde seus primeiros livros da década de 1980, nos quais dialogava com Marx e Althusser, até os mais recentes, quando realiza uma leitura semiótica das obras de Agamben, Foucault e Negri/Hardt. Problematiza ainda o uso atual das redes sociais, discute o papel da ciência diante das fake News e confessa confiar que o amor pelo conhecimento e a aposta na educação são antídotos aos fundamentalismos que emergem em diferentes instâncias da sociedade.

\section{Palavras-chave}

Semiótica. Ciência. Política. Pragmaticismo. Charles Peirce.

"O signo é uma espécie de coisa, mas, em maior ou menor medida, sem escapatória possível, seja ele uma palavra ou uma imagem, o signo não pode ser a coisa que ele designa. Fica sempre um resíduo, uma sobra, algo restante que o signo não pode recobrir. Desde o nível de deslocamento radical entre signo e referente, só unidos por força de uma convenção, até o nível de uma relação de similitude no limiar da quase-identidade entre signo e referente, há sempre uma fissura que pode ser mais larga ou mais estreita, mas sempre uma fissura, separação, desgarramento. É no descarnamento dessa fissura que se entranha o trabalho do poeta e do artista". (SANTAELLA, Miniaturas, 1996, p. 44)

É nessa fissura que se tece a obra de Lúcia Santaella. A autora enfrenta o trágico da fissura não na perspectiva da dívida que o signo nas leituras mais apressadas parece ter com seu referente, mas na afirmação de que o signo é vida, é o que resiste à nossa finitude: um signo sempre renasce em outro, e isso infinitamente. 
Desde Produção de linguagem e ideologia (1980) e Arte \& Cultura: os equívocos do elitismo (1982) até o recente Haroldo de Campos: para sempre (2019), em 51 livros e mais de 400 artigos publicados em periódicos nacionais e internacionais, a autora exercitou a ética do intelecto, mantendo a inteligência conectada com as principais experiências de vanguarda estética e de descobertas científicas - das teorias das linguagens às tecnologias da Inteligência.

Conectada com o devir do mundo, a obra de Santaella mira o futuro não apenas em função das escolhas temáticas que faz, mas sobretudo em função de um tipo de pensamento que adota - o pensamento semiótico - que, irrequieto, coloca em seu âmago a diversidade e em seu destino a esperança de um mundo mais razoável. Diversidade e razoabilidade concreta, oposição a maniqueísmos, reconhecimento da capacidade de autocorreção da ciência, defesa da mediação como valor ético-político são vetores que norteiam sua obra, desde os primeiros textos em que faz dura crítica ao elitismo até sua declaração de amor ao poeta Haroldo de Campos, em seu livro mais recente: "Muito ou quase tudo de minha paixão intelectual devo a Haroldo de Campos, pois foi dele que aprendi a extrair o mel insuspeitado da semiótica [...]". (SANTAELLA, Haroldo de Campos: para sempre, p. 68).

Nesta entrevista concedida à Intexto, Lúcia Santaella esclarece as razões por que a Semiótica, ainda que perdendo importantes espaços institucionais nas últimas décadas, permanece oferecendo alternativas consistentes para quem tem amor pelo conhecimento e aposta na educação como alternativa à ignorância que leva aos fundamentalismos reinantes. Santaella também faz defesa veemente de uma ciência cujos protocolos e métodos permitem sempre a correção de seus próprios erros e falhas. É por essas razões - a consciência do falibilismo e a prática constante da autocorreção - que o trabalho do cientista resiste às fake news e se apresenta como dispositivo político de resistência.

Os vínculos entre semiótica e política também são avaliados por Santaella nesta entrevista tanto na abordagem das fake news e no uso das redes sociais quanto do debate propriamente teórico. Esta passagem é bem curiosa porque estamos acostumados a associála aos estudos da linguagem; entretanto, ao longo de sua obra, desde os seus primeiros textos, os vínculos indissociáveis entre linguagem e política aparecem transversalmente. Nesta entrevista, Santaella traz à cena seus diálogos com Marx, Althusser, Agamben, Foucault e Negri para mostrar que - mesmo sem dizer seu nome - há um fazer semiótico-político em curso.

A todos, uma boa leitura! 
No artigo Memória e perspectivas da semiótica no Brasil, publicado na Revista Intexto em 2016, você faz uma genealogia das linhas de força que mantêm atuante a pesquisa em semiótica no Brasil. Nele, você identifica grupos que "não sofreram rupturas e descontinuidades, mantendo-se vivos do passado ao presente". Entretanto, dos anos 1970 para cá, o pensamento semiótico parece ter perdido espaços importantes: muitos cursos de graduação retiraram de seus currículos a disciplina, PPG e linhas de pesquisa modificaram seus focos em detrimento da semiótica, fóruns e instituições nacionais não têm reunido pesquisadores em torno de GPs de semiótica. Criticamente, como você avalia as perspectivas da área e que ações institucionais sugere para a formação qualificada de novos semioticistas?

Meu diagnóstico, que repito sempre, porque o julgo até certo ponto correto, é simples: a dificuldade de institucionalização da semiótica advém do fato de que não existe uma profissão de semioticista, ou seja, ninguém pode reivindicar essa profissão no mercado de trabalho. Sobraria, talvez, para quem tem uma formação sólida na área, a função pedagógica: ser professor de semiótica. Entretanto, se os cursos se fecham para essa disciplina, cria-se um círculo vicioso. Entretanto, a questão que fica é o porquê isso se dá. A semiótica é uma ciência transdisciplinar como são interdisciplinares a teoria dos sistemas, a teoria da complexidade, a cibernética etc. Mas há na semiótica algo que não aparece nessas outras que, sob o aspecto da transdisciplinaridade, lhe são coetâneas: o objeto de estudo da semiótica são as linguagens humanas que existiram e que continuam existindo. Se entendermos linguagens no sentido de sons, imagens, verbo, suas misturas e todos os campos em que se manifestam, tais como as linguagens da sonoridade - música, canto, rádio -, da visualidade - desenho, gravura, pintura, fotografia, arquitetura - então, as linguagens do espetáculo e da cena - circo, teatro, dança, ópera - e as linguagens do audiovisual cinema, TV, vídeo -, as linguagens verbais e seus híbridos - livros, jornais, publicidades, então, todas essas áreas, e outras mais e suas misturas possíveis, que têm entrada nos cursos de formação universitária, deveriam conter disciplinas de semiótica, pois entender como suas linguagens funcionam deveria ser fundamental para a formação dos profissionais em 
cada uma dessas áreas. Infelizmente não é isso o que tem acontecido. Cada área fecha-se em si mesma, naquilo que julga relevante para o mercado de trabalho e a semiótica tem sido dispensada como um acessório desnecessário ou, pior do que isso, como um estorvo. Isso pode ser resumido naquilo que se concebe como formação universitária e que acaba revelando uma lógica imediatista. Lógica, de resto, que está sendo castigada, pois, com a transformação acelerada da realidade social, uma formação voltada para o mercado de trabalho falha, pois, quando o estudante sai da universidade, o que sua formação lhe forneceu já não é mais válido para as novas tarefas que o mercado lhe apresenta.

\section{Embora a formação moderna da semiótica venha do pensamento do} século $\mathrm{XIX}$, foi depois da primeira metade do século $\mathrm{XX}$ que ela conquistou espaços consideráveis nas instituições de ensino e em centros avançados de pesquisa. Esse pensamento, parece-me, coincidiu com o auge das experiências vanguardistas, do Nouveau Roman ao Concretismo. O declínio da semiótica francesa já nos anos 1970 acentuado nos anos 1980 também coincidiu com o fim das vanguardas. É uma coincidência? Você que escreveu (Arte) \& (Cultura): equívocos do elitismo (1982) problematiza de que maneira essa ascensão e queda da semiótica considerando o contexto cultural e artístico do século XX?

O pensamento semiótico já começou a brotar no século XIX, com C. S. Peirce e alguns linguistas da União Soviética preocupados com o papel da língua na vida social. Afinal, a Revolução Industrial já estava trazendo novas tecnologias de linguagem (telégrafo, fotografia, meios de impressão sofisticados para o jornal) que começavam a competir com os sistemas de signos tradicionais. Creio que isso despertou novos pensamentos sobre as linguagens humanas. Isso faz sentido porque, quando se deu o boom da semiótica nos anos 1960-70, os meios de comunicação de massas, incluindo cinema, rádio, televisão e revistas, tinham presença significativa na vida social e pessoal. Isso reclamava por teorias dos signos e significação. Muitos aderiram afoitamente à semiótica na época para, cessada a onda, abandoná-la. Entretanto, isso não significa que a semiótica tenha assistido à sua decadência. Ela permanece como uma área de pesquisa e de conhecimento, infelizmente, sem que tenha muito respaldo institucional. Meu livro, que você menciona acima, nasceu no contexto pós- 
ditadura. Certamente, mesmo quando não menciono explicitamente a semiótica, ela funciona como uma espécie de guia do meu pensamento. Nessa época já tinha absorvido devidamente a semiótica no contexto da filosofia de Peirce e isso, sem dúvida, estava subjacente à crítica que busquei fazer, nesse livro, à ausência de renovação das ideias em vigor pós-ditadura. Algo estava alvorecendo e o pensamento em voga mantinha-se estacionário.

Em seu livro Temas e dilemas do pós-digital: a voz da política (2016), você parece indicar rumos para a semiótica junto aos pós-estruturalistas, trazendo à cena de sua reflexão autores como Michel Foucault, Giorgio Agamben e Antônio Negri. Por coincidência, três autores que jamais separaram os processos de significação da política. Você concordaria com o postulado de Gilles Deleuze e de Felix Guattari de que "a linguagem é caso de política antes de ser caso de linguística" (1980)? Peircianamente falando, a forma semiótica dessa política que antecede a linguística não seria o próprio pragmaticismo?

Creio que Deleuze e Guattari opunham-se aí ao centramento na linguística como conhecimento exclusivo da língua em abstrato. Toda linguagem é política porque é situada. Nenhuma linguagem encontra-se ou vem do limbo, portanto, está sempre implicada nas contradições das sociedades em que existe. Isso é político. Esse livro Temas e dilemas nasceu da percepção de que estava na hora do digital fazer um balanço autocrítico, portanto, político. Que promessas foram cumpridas e quais foram traídas? Que efeitos sociais estavam produzindo? Ora, como se tratava de enfrentar uma questão política, fui às raízes. Busquei os pensadores mais influentes para desenhar a questão do político antes de entrar especificamente nos desafios do pós-digital. Peirce, por seu lado, era um filósofo lógico. Não estava diretamente ligado a áreas de conhecimento regionais. Mas creio que a ideia que você levanta de encontrar uma chave de um pensamento político no pragmaticismo de Peirce deve fazer sentido. Isto porque, para ele, o pragmaticismo é uma consequência da relação indissociável da lógica com a ética e a estética, ciências que estudam os fins últimos que guiam os propósitos humanos. Propósitos têm, indissociavelmente, cunho político. 
A semiótica peirciana, diferente da semiologia francesa bastante associada

à literatura e à linguística, alargou seu escopo de atuação sobretudo na interface com as ciências cognitivas e as tecnologias da inteligência. Tal aliança a mantém potente em áreas lamentavelmente ainda afastadas dos campos da comunicação e das letras, um pouco menos do campo do design. Você que passou pelas letras, pela comunicação, pelo design e hoje coordena um programa de pós-graduação em tecnologias da inteligência, que caminhos aponta para a semiótica nesses campos?

Se alguém conseguir me convencer que é possível haver cognição sem signos, agradeceria, pois os biossemioticistas peircianos já demonstraram que a vida biológica depende de operações sígnicas, o que dizer, então, das culturas humanas. Tecnologias da inteligência são tecnologias de linguagem. Programas de computador são linguagens, sem elas, o computador não passaria de um objeto despropositado e hoje a inteligência artificial está tornando evidente que o computador nunca foi mera ferramenta, tanto é que, no nível de desenvolvimento de sua história, hoje computadores aprendem, são capazes de autocorreção. Mesmo que não deem a isso o nome de semiótica, ela está lá, desde sempre presente.

Peirce talvez tenha sido um dos filósofos que melhor articulou em sua arquitetura filosófica procedimentos metodológicos capazes de garantir rigor à investigação científica realizada em perspectiva interdisciplinar. 0 que vemos no campo de conhecimento da comunicação, que se fragmenta cada vez mais na direção de uma formação profissionalizante, é o contrário disso. Este é mais um indício de que o pensamento semiótico tem perdido capacidade de incidir sobre a produção de conhecimento no campo da comunicação? Há experiências hoje no país que consubstanciem outros projetos. Do ponto de vista das ciências normativas, que 


\section{procedimentos deveriam ser esses, considerando as diferentes} experiências que já tivemos no país.

Toda a arquitetura filosófica de Peirce e em especial a semiótica, que ocupa o coração dessa arquitetura, funcionam como uma cartografia cognitiva que, com base na ciência dos signos, permite dialogar e interagir com quaisquer áreas do conhecimento. Essa afirmação deve soar ousada porque as ciências se fragmentaram, cada uma protegida dentro de sua própria casa. Sem minimizar a importância da especialização, a comparação comparece para marcar que a obra de Peirce opera em outro nível, ou melhor, tanto no meta nível quanto no infra nível. Ao mesmo tempo que fornece princípios para compreender o pensamento e o conhecimento em geral, também nos possibilita um meta olhar sobre todas as formas concretas de desenvolvimento do conhecimento. Apesar da dilatação cada vez maior do campo empírico da comunicação, como área de saber, não apenas no Brasil, ela optou por seguir o exemplo da regionalização do conhecimento, próprio das outras ciências. 0 problema que surge do divórcio imposto à semiótica pela comunicação é que não há comunicação e nem cultura sem signos. Portanto, ao se alijar da semiótica, quem perde com isso é a comunicação, porque a semiótica, por seu lado, continuará estando equipada com conceitos e guias metodológicos impecáveis e poderosos para a descrição, análise e avaliação dos processos de comunicação humana e não humana. É muito bom lembrar disto em tempos de pandemia.

Os currículos dos cursos de comunicação já estiveram fundamentados na interface com outras áreas do conhecimento - sociologia, psicologia, filosofia, por exemplo; já estiveram fundamentados no funcionamento de diferentes mídias - jornal, rádio, televisão -; já buscaram seu obscuro objeto perdido. Não estaria na hora de se pensar em uma organização do conhecimento fundamentada nas linguagens e em suas matrizes? 0 que 0 pensamento semiótico tem ainda potencialmente a oferecer para a investigação em comunicação?

Há uns anos, desenvolvi um programa de pós graduação em comunicação tendo por base as três matrizes. As linhas eram organizadas em linguagens sonoras (música, trilhas, rádio, áudio publicidade), linguagens visuais (pintura, foto, cine, TV, vídeo) e linguagens 
verbais (jornalismo, literatura etc.). Tínhamos um laboratório espetacular de sonoridade eletroacústica e outro de computação gráfica, ambos pioneiros em academias brasileiras. Portanto, o que havia aí era uma interdisciplinaridade de sistemas de linguagens, suas tradições e seus contextos históricos que conversavam entre si. Isso, de certa forma, antecipou a tendência crescente dos programas interdisciplinares no Brasil, assim como antecipou o advento da hipermídia como linguagem das redes digitais. Entretanto, chegou uma hora em que o programa se viu condenado pelo estigma de que não cabia na área de comunicação. Estava vazando suas fronteiras bem protegidas. Ademais, isso coincidiu com a entrada da onda das mídias, uma verdadeira mídia mania que tomou conta de muitos programas. Mas o problema de fundo é mais complexo. Costuma ainda haver uma dissociação entre os estudos das linguagens e o estudo de conteúdos temáticos, como se o estudo das linguagens e dos signos fosse meramente formal e não desse conta dos efeitos psíquicos e dos intercursos sociais e políticos das linguagens. Para muitos, de fato, os signos ficam no ponto cego da retina. Nesse caso, a semiótica não tem mesmo nenhuma porta de entrada.

seu livro $O$ que é semiótica (1983) ainda é um dos mais conhecidos e difundidos de sua carreira. Ele, de fato, foi fundamental para a difusão da semiótica peirciana no Brasil, ao lado dos trabalhos precursores de Décio Pignatari. Nele, a abordagem semiótica dá-se a partir da Teoria Geral dos Signos e da Fenomenologia. Depois, com A assinatura das coisas: Peirce $e$ a Literatura (1992), A teoria geral dos signos: semiose e autogeração (1995), Percepção: Uma Teoria Semiótica (1993), Estética: de Platão a Peirce (1994), O método anticartesiano de C. S. Peirce (2004) você foi cercando o problema semiótico considerando as diferentes instâncias da arquitetura filosófica de Peirce. Passados quase quarenta anos de $\boldsymbol{O}$ que é semiótica, o que você diria para alguém que queira começar a estudar semiótica? 0 primeiro passo seria mesmo a Faneroscopia e a Teoria Geral dos Signos ou seria a compreensão de sua arquitetura filosófica? 
De fato, $O$ que é semiótica continua a vender, depois de 47 anos, apesar de existirem vários pdfs desse livro nas redes. Mas que ele seja o mais popularizado, dentre todos os meus livros, é um sintoma de que os leitores gostam mesmo é de facilitações. Há outros sinais desse sintoma. Faltou na sua lista acima o livro Semiótica aplicada (2 $2^{\mathrm{a}}$. edição ampliada, 2019), outro livro que vende muito e que, também é facilitador. Não estou desmerecendo os meus livros, eles foram guiados pela ética do intelecto, mas foram escritos como introduções. Escrevo para um público universitário, sobre isso não tenho dúvidas. 0 escritor pré-seleciona seu público. Passei minha vida nesse ambiente e é ele que conheço bem. Daí minha crítica ao sintoma, pois os leitores costumam parar nas introduções sem prosseguir, mesmo quando se declaram interessados em semiótica. Mas isso não se restringe aos meus livros. Sabemos muito bem, sem cobrirmos o sol com a peneira, que os alunos brasileiros não desenvolvem qualquer paixão pela leitura e pelo aprofundamento no conhecimento dos autores que citam. Tudo vira uma festa leviana de citar nomes sem ter nem mesmo lido pelo menos partes da obra dos autores que citam. Se isso acontecesse só com os estudantes já seria lamentável, mas vai além. Tudo isso não parece outra coisa senão o resultado do desprezo que a cultura imediatista provoca em relação à paciência do conceito. Quanto ao ponto em que se deve começar a transmissão do pensamento de Peirce, depende da finalidade da transmissão. Se é para um curso de filosofia, sem dúvida, pelo edifício filosófico. Se é para áreas que buscam o diálogo com a semiótica, então, deve-se começar pela fenomenologia e, então, para os signos. Mas neste caso é ainda preciso evidenciar que a semiótica não é autossuficiente, pois se satura na ética e a ética na estética, estas que são as ciências dos fins e ideais humanos.

A semiótica é acusada pelos que a desconhecem de meramente classificatória, embora ela seja desde o século XIX também uma ciência do movimento, da transformação, do devir. Poderíamos denunciar o desconhecimento da área pelos que assim a caracterizam. No entanto, se considerarmos muitos dos trabalhos não-semióticos escritos como se semióticos fossem, talvez precisássemos realizar uma autocrítica muito rigorosa dos trabalhos que aceitamos em congressos e revistas, das práticas em sala de aula implementadas. Mas também exigiria uma reavaliação da história da difusão da semiótica no Brasil. Introduzir a 
semiótica no país pela Teoria Geral do Signo pode ter contribuído para isso?

A semiótica, de fato, é classificatória. Para Peirce, há quatro níveis em todas as ciências. 0 teorético (qualquer ciência depende da criação de conceitos fundadores de seu campo), classificatório (todo campo científico é demarcado em zonas diferenciadas que se interligam), descritivo (pressupõe os anteriores, caso contrário a descrição do campo fica desgovernada) e aplicado (quando os níveis anteriores sustentam as aplicações empíricas). A base teorética da semiótica encontra-se na fenomenologia, uma fenomenologia a céu aberto, bem distinta da competidora continental que ficou bem mais famosa, embora ainda presa a um sujeito transcendental. A base teorética da semiótica encontra-se também nas definições de signo. Delas derivam a classificação dos signos que caracterizam distintos modos de ação sígnica. Signo é semiose, ou seja, é a ação do signo, a ação de ser interpretado. Cada tipo de signo recorta a realidade de um certo modo e em uma certa medida, portanto, no seu caráter mediador, traz para nós distintas figurações da realidade. A crítica corrente que se faz das classificações da semiótica de Peirce provém de um desconhecimento do que elas são e como agem. Sem estudar muito bem o que são classes naturais que estão na base das classificações de Peirce, já vão lançando suas críticas com uma ideia pré-concebida de classificação como algo estático, um decalque. Nada mais distinto a isso do que a noção de classificações onipresentes, todas operando simultaneamente, levando-se em consideração que umas operam com mais domínio do que outras em dadas situações. Portanto, para falar das classificações peircianas, é preciso levar em conta que elas exigem uma atividade heurística daqueles que as empregam. Não sei se Peirce é introduzido pela Teoria Geral dos Signos, aliás, no meu caso, um livro que escrevi, antes de tudo, para mim mesma, com os manuscritos ainda não publicados de Peirce nas mãos. Queria perscrutar com obstinação e compreender o sistema altamente integrado da semiótica de Peirce. Mas esse sistema pressupões um conhecimento bem profundo da fenomenologia. Talvez o equívoco esteja aí: sair correndo para as célebres divisões triádicas sem passar o tempo necessário para absorver, por meio das categorias, o que significa e que consequências traz pensar triadicamente.

\section{Não falei na questão anterior de Matrizes da Linguagem e Pensamento} (2001), vencedor do prêmio Jabiti em 2002, porque gostaria de você descrevesse como foi o trabalho de produção desse livro que realiza em 


\section{filigranas uma análise semiótica que tem a felicidade de expressar o} próprio movimento do pensamento.

Levei 27 anos para completar esse livro. Ele foi crescendo muito gradativamente e interrompido, várias vezes, por outros interesses intelectuais que me pareciam mais urgentes. Tenho formação em música desde criança. Também me diplomei em letras e literatura. Faltava uma formação segura em visualidade e todas as suas manifestações midiáticas. Isso exigiu muito de mim, embora tenha tido a sorte de ter alunos e orientandos brilhantes nesse campo, desde artistas, fotógrafos, cineastas até geólogos. Aprendi muito com eles. Esse livro foi o meu primeiro Jabuti. Fui finalista sete vezes e premiada quatro. Esses bichinhos estão aqui do meu lado na estante piscando para mim. Eles têm um ar humilde, como uma lição de que escrever é um ato de coragem e responsabilidade. Em um dos concursos, um livro meu competiu com outro também meu. Muito engraçado. Não sabia por qual torcer. Matrizes, na verdade, nasceu da necessidade de criar um campo (classificatório, de resto, um solo fértil para os críticos das classificações) de análise capaz de fazer uma mediação conceitual e classificatória entre os conceitos muito abstratos de Peirce e os campos dos sistemas empíricos de signos. Cheguei, graças ao escrutínio das classes de signos de Peirce, a 81 modalidades de sistemas de signos, sonoros, visuais e verbais. Mas o livro, de fato, não é para leitores impacientes.

Ao acompanharmos sua produção intelectual, com 71 livros publicados ou organizados, podemos observar uma constante: o olho no futuro e a aposta esperançosa em uma maior razoabilidade concreta para o mundo. Da escolha dos temas às perspectivas teóricas com as quais você dialoga, este traço é constante. Mesmo quando recupera, em um de seus últimos livros, o trabalho de Haroldo de Campos (2019), é para dele extrair toda a potência de transformação que a obra do poeta preserva. Como ocorre a seleção dos problemas semióticos que você decide encarar?

Acho que herdei de Peirce o amor pela inteligência, como ela cresce, como ela erra, falha, pode degenerar, mas sempre com a tendência de autocorrigir-se. A filosofia de Peirce, seu falibilismo, que tem suas bases nas operações próprias de todo signo, sempre parcial e sujeito a erros, a mentiras e equívocos, ajuda-nos a procurar a verdade, que é sempre adiada, 
mas é justo por isso que se mantém a busca. Não a verdade como dogma, mas a verdade como força de atração por tudo aquilo que é admirável.

\section{A ciência hoje no Brasil passa por uma severa crítica, por um violento} processo de desconstituição em nome de novos fundamentalismos político-religiosos. A reflexão, o reconhecimento do falibilismo como constitutivo de todo o pensamento científico, a mediação, o antifundacionismo, a esperança equilibrista de Peirce resistirão?

A desconfiança na ciência e a prisão em fundamentalismos de quaisquer espécies é fruto da ignorância. Vivemos em bolhas de crenças e convicções. Mas há bolhas amplas, dilatadas, porosas, expostas a dúvidas e à escuta do outro. De outro lado, há bolhas asfixiantes, fechadas à diferença, homofílicas, só gostam do que é espelho e assim mesmo espelhos bem estreitos. Apenas processos educativos honestos e o amor pelo conhecimento seriam capazes de tirar os homofílicos do seu próprio espelho. Para isso, no entanto, é preciso vontade e investimento político bem fundamentado para a educação. De outro lado, devemos perceber que a educação hoje encontra grandes competidores nas mídias de entretenimento, alimentadas pelo capital e a publicidade comandada por algoritmos de inteligência artificial, que seduzem com uma voracidade diante da qual a busca do conhecimento soçobra.

\section{O modelo científico de Peirce não é antropocêntrico. Então sua esperança} também não se reduz ao devir do homem. Seria possível hoje identificar que a era do antropoceno pode estar sendo superada? Qual sua leitura semiótica do tempo presente?

Minha leitura é que o mundo que habitamos tornou-se arquicomplexo. Com isso procuro levar ainda mais longe o diagnóstico de Lipovetsky sobre os tempos hipermodernos. Os signos e as mídias cresceram imensuravelmente, hoje múltiplas interpretações de assuntos diversificados povoam não apenas as redes, mas também revistas científicas e livros confiáveis. Existem teorias incomensuráveis, distintas, até mesmo opostas e impossível de serem refutadas. Conforme a ciência avançou na sua investigação da realidade, esta foi se mostrando cada vez mais complexa, difícil de caber em conclusões 
consensuais e muito menos peremptórios. Diante disso, ficamos no fio da navalha porque é, de fato, fino o fio para não se cair no mero relativismo. Nas ciências humanas e sociais não é diferente, pois multiplicam-se as tendências filosóficas e teóricas. Precisamos aprender a fazer escolhas lúcidas de acordo com os propósitos que guiam nossa pesquisa. Voltando a Peirce, sua filosofia tem traços de extrema originalidade pela qual está pagando o seu preço. Embora a semiótica, a ética e a estética (que não se confunde com uma doutrina do belo) sejam ciências que pensam os ideais humanos, a noção de semiose, ação do signo, é tão ampla que se aplica desde o nível das ações sígnicas mais rudimentares, incluindo também a semiose das plantas, dos animais, até atingir as semioses mais complicadas, as humanas, cuja complexidade se deve muito ao fato de que o humano é o animal que mais erra na biosfera. Embora a semiose seja um modelo lógico condensado, ele é tão amplo que permite pensar desde os rudimentos da ação do signo até os níveis ultra complexos. Por isso nos fornece elementos para enxergar que o humano não está no centro do universo. Para isso não poderia haver evidência maior do que um mero vírus, um parasita inorgânico, atacar a humanidade e a colocar em estado de fragilidade e profunda vulneralidade.

\section{Falamos anteriormente sobre seus livros de semiótica em sentido estrito;} mas você escreveu muitos outros: sobre estética, sobre inteligência artificial, sobre política, sobre comunicação, sobre imagem, sobre arquitetura, sobre games, sobre psicanálise, sobre cultura, sobre linguagens líquidas; está próxima também literatura. Como são suas experiências com artistas? Como essas experiências repercutem no seu fazer científico e no desenvolvimento da semiótica?

Não sou artista. Nunca cultivei esse desejo, por isso nunca me vi tentada a sustentar esse desejo. Nascemos para algumas coisas e não para outras. Convivi e convivo com muitos artistas, inclusive os mais rebeldes com o status quo da arte. Fico muito rente a eles. Ganho com isso o que não tenho. Eles nos ensinam a olhar para onde sopram os ventos vivos da criação. Na realidade, sou pesquisadora e, por consequência, escritora. Brinco que sou uma fêmea teórica. Parece autoironia, mas na realidade é aí que me sinto mais confortável. Além disso, tenho uma inelutável, cansativa e exasperante curiosidade intelectual. Isso me leva por geometrias que nada têm de repetitivas ou lineares. Meus livros são frutos disso. Quanto ao desenvolvimento da semiótica, não tenho domínio nenhum sobre isso e, para dizer a 
verdade, não gasto neurônios para pensar nisso. Adoto uma frase de Chico Buarque, longe de querer me comparar com a grandeza dele, mas a frase cabe: "faço uma canção, ponho no mundo e ela cai na vida". Assim também, ponho muito esforço e sinceridade no que faço. Escrevo os livros, eles caem no mundo e lá eles adquirem uma vida própria. Se tiver ansiedade em relação aos que já se foram, perco o sonho e a energia para o que virá.

Retomando a pergunta anterior, há trabalhos seus em que a teoria semiótica está explicitamente no centro. Mas há outros em que ela tece o raciocínio, mas não aparece como objeto específico de reflexão. Há talvez uma semiótica que não diga seu nome. Uma semiótica que não diz seu nome é um destino possível para a pesquisa em semiótica no contexto da pesquisa no Brasil?

De fato, há semióticas implícitas quando os autores estão lidando com signos e os interpretando com muita competência, sem usar o nome ou conceitos de semiótica. São semioticistas congênitos. No meu caso, os conceitos semióticos devem estar hoje, com toda naturalidade, na minha corrente sanguínea. Mas tenho muito curiosidade e até ansiedade para conhecer e penetrar nos pensamentos alheios. Evidentemente não em quaisquer pensamentos, mas naqueles de pessoas que entregaram boa parte de suas vidas para construí-los e entregá-los ao público leitor. Temos que buscar nossos guias. E ficar vida afora em um só guia produz fanatismo, algo nocivo no mundo do conhecimento. 0 que deve acontecer é que absorvi de tal modo a maneira de pensar triádica, ou melhor, em continuidade, pois a chave da semiose é a continuidade, que, mesmo quando escrevo sobre outros temas, esse rio subjacente está sempre presente. Quanto ao Brasil, de fato, não tenho receitas intelectuais e nem outras para ele. A vida intelectual caminha pelas escolhas de cada um. Aliás, são elas que nos definem como intelectuais.

Há outras e mais recentes incursões suas na vida intelectual brasileira. Essas ocorrem nas redes sociais. Lá é possível observar as primeiras impressões sobre as vidas reclusas em período de isolamento social, sobre fatos do cotidiano, sobre cinema e outras artes. O tom, em geral, é de primeiras impressões, ensaístico, tentativo. Você considera as redes 
sociais como espaço de teste para ensaios ou o próprio meio pode vir a ser um espaço privilegiado para a reflexão rigorosa tal como defendido em 0 método anticartesiano de C. S. Peirce (2004)?

Sempre me constrangeu falar ou escrever em primeira pessoa. Afinal, não sou nenhuma celebridade para as pessoas estarem interessadas na minha pessoalidade ou nas fofocas de minha vida. Fofoca é para o mundo do bigmassbusiness. Entretanto, a pandemia veio com tal voracidade e nos pegou tão desprevenidos que comecei a escrever um diário de bordo. Uma parte foi publicada no blog Sociotramas. Palavras vieram em nosso socorro no isolamento, com elas procuramos perfurar as paredes que nos prendiam e continuam a nos prender. Encontrei no Facebook um lugar de conversação comigo mesma, mas com alguma expectativa de diálogo com o outro. Isso não significa que tenha pensado quaisquer redes como substitutas do que nos cabe como acadêmicos continuar a desenvolver: o pensamento bem fundamentado, cuidadoso e a tarefa de colocá-lo no mundo para o debate público com nossos pares. Esse é o mundo que se caracteriza como nosso. De um lado sou nietzschiana, penso que a praça pública não é o nosso lugar e, afinal, também li Foucault e aprendi sua lição sobre a responsabilidade em relação àquilo que pensamos e escrevemos.

\section{Muitas manifestações suas nas redes sociais provocam polêmica, das ciclovias à crítica ao desmonte da ciência no Brasil em curso. Você considera a rede social um espaço propício à dialogia?}

Procuro não pensar nessa passagem das ciclovias, uma perseguição de que fui vítima, sem que ninguém parasse para pensar sobre o absurdo de encher a cidade de vermelho, sem nenhum planejamento a não ser o oportunismo de colocá-las rapidamente em regiões de universidades ricas para buscar a aderência de jovens imbuídos do sonho de que andar de bicicleta seria o caminho da sustentabilidade em uma cidade frenética e desordenada como São Paulo. Não vou transformar esta resposta em uma justificativa da qual não necessito. 0 que posso dizer é que meus filhos foram perseguidos. Livros meus foram censurados em universidades que têm a pretensão de serem engajadas. Enfim, o texto é bastante engraçado e, de fato, me faz rir. Infelizmente, não foi isso que provocou nos perseguidores políticos do momento, tão atentos a qualquer crítica que viralizaram meu texto em dois dias. Mais risível ainda é que, na época, fiquei mais famosa por esse incidente do que pelas dezenas de livros e centenas de artigos que escrevi. Costumo dizer que isso não 
é outra coisa senão a cara do Brasil. Não sou afeita a polêmicas. Aprendi com Serres que elas não levam a nada. Pura perda de neurônios e de tempo. Mas há momentos em que nosso fígado precisa ser desopilado. Os absurdos nos assaltam de tal modo que as palavras nos asfixiam se não saírem. É o que tem acontecido agora no estado de miserabilidade em que fomos jogados neste país. Até voltei para o Twitter para buscar um cantinho de resistência, pois é lá que os pontos estão sendo contados.

A ideia semiótica de mediação, inseparável de um raciocínio triádico, associada ao princípio do sinequismo, que evidencia haver continuidade criativa entre a singularidade da invenção e a transformação dos hábitos que organizam nossa vida em comum, parecem parametrar ao longo de sua obra uma espécie de ética científica e política. É essa a sua ideologia?

Não sei se chamaria de ideologia que compreendo como um sistema estreito ou mais amplo, depende do repertório de quem a professa, de representação de mundo. Claro que tenho algo desse tipo, mas, de fato, não se trata de uma representação estática, mas um sistema permanente de busca e de transformação. Sinto-me privilegiada e sou imensamente premiada pela convivência com jovens ansiosos por aprender, e mal sabem eles o quanto me ensinam. Acho que é um modo de vida que coloca em prática a ideia de sinequismo peirciana como continuidade transformadora. Isso não significa que o caminho é fácil. Há nele muitos tropeços, muitas pedras no meio do caminho sobre as quais não vale a pena falar.

Em seus primeiros livros - (Arte) \& (Cultura): equívocos do elitismo (1982) e Produção de Linguagem e Ideologia (1980; 1996) - parecia haver uma certa necessidade de acertar contas com o marxismo, ideia abandonada em seus escritos posteriores. Era apenas espírito do tempo ou a figura de Karl Marx ainda lhe aparece como um espectro? Sob que termos seria hoje possível - e, talvez, necessário - repensar o comum e o coletivo à luz do marxismo e do pragmaticismo peirciano?

Um dia sonhei em escrever um livro para evidenciar que o pensamento de Peirce, devidamente explorado, seria capaz de fazer a mediação entre Hegel e Marx. Era jovem e não 
podia medir a ambição descabida do projeto. Uma vida inteira não seria suficiente para isso. Li Marx naquela época, de fato, estudei Marx, não fiquei apenas nas orelhas e nos slogans. Tive aulas particulares com um sociólogo brilhante sobre Marx. Assim como tive aulas de Hegel. Vivi a fenomenologia do espírito como a via crucis do espírito, principalmente porque na época, com o coração inquieto, estava mais interessada no I Ching do que em Hegel. De todo modo, não abandonei Marx. Seu pensamento crítico foi fundador, mas o que ainda prefiro é o Marx da educação dos cinco sentidos. 0 problema é que, embora alguns elementos cruciais de sua crítica ainda persistam, do século 19 para cá, o capitalismo deu saltos de complexidade que barram o entendimento dos leigos e os velhos receituários não cabem mais. Para compreender o turbo capitalismo ou capitalismo tardio temos que providenciar aulas particulares com especialistas, muito embora não deixemos de sofrer seus efeitos, mesmo sem compreendê-lo no seu real funcionamento.

Em Produção de Linguagem e Ideologia (1980; 1996), o marxismo vem já transformado pelo estruturalismo de Louis Althusser. Lá, vislumbra-se um Althusser semioticista nos seus argumentos, ainda que bem pontuados os limites dessa espécie de pensamento semiótico. Esse gesto que reinventou Althusser como semioticista é semelhante ao usado para ler hoje Foucault, Agamben e Negri em Temas e dilemas do pós-digital: a voz da política (2016)?

Sou semioticista, mas não só semioticista. Pelo menos procuro, faço um belo esforço para me desprender de minhas crenças, mesmo que saudáveis, quando me ponho a compreender um autor. Esse é o caso de Agamben, um autor muito mais complexo do que pensam aqueles que o citam levianamente e que, inclusive, andam recentemente criticando, sem que tenham se dado ao trabalho de queimar as pestanas para compreender o pensamento de Agamben nos seus próprios termos, e não a partir de velhas dicotomias mal resolvidas. 0 que dizer, então, das bíblias de Negri sobre Império e Multidão? Quanto tempo é necessário para compreender suas propostas, além das genealogias de pensamento de que partem e que é também preciso conhecer?

Em um de seus mais recentes livros - A pós-verdade é verdadeira ou falsa? (2018) - há um gesto intelectual cuja produtividade para os estudos 
semióticos parece-me fundamental: você recupera o paradigmático texto de Hannah Arendt Verdade e Política (1972), onde a autora reflete sobre a verdade factual, para inseri-lo nas tramas semióticas de Peirce. Esse gesto, além de circunscrever com precisão a abordagem de Arendt, nos possibilita reconhecer a existência de três modos de referência: a apresentação, a indicação e a representação, bem como seus desdobramentos nas artes, na comunicação, na filosofia e na ciência. Para além do livro, gostaria de lhe ouvir falar, desde a perspectiva do sinequismo, sobre as semioses que colocam em relação essas três perspectivas de verdade. Que novos hábitos estão elas em vias de constituir?

Na questão da verdade, a mais perfeita perspectiva sinequística, princípio da continuidade tout court, encontra-se na filosofia, cujo mister é justamente refletir em distintas modulações, no correr dos séculos, sobre, entre outras, justamente a questão da verdade. A arte não tem nada a ver com verdades que lhe são externas, pois sua tarefa é criar sua própria verdade. A ciência tem protocolos e métodos que lhe permitem corrigir seus erros e falhas. Por isso, a ciência não mente, pois quando mente, possui meios internos para se corrigir. 0 que resta? 0 mundo dos fatos, dos acontecimentos que atravessamos cotidianamente e que nos atravessam. Por isso, Arendt reivindica a discriminação da verdade factual. Só os fatos e as tabelas da lógica podem ser verdadeiros ou falsos. As tabelas da lógica porque criam suas próprias convenções. Os fatos porque lidam com signos indiciais cujos referentes podem ser verificados, checados. Isso nos livra de pensar que a revoada de pós-verdade tenha atacado como gafanhotos exterminadores todas as atividades e áreas da produção humanas. A pós-verdade e as fake news só atacam majoritária e perniciosamente a política, mas a política, desde sempre, como nos diz Arendt, é a arte da mentira. Infelizmente os seus efeitos sociais são nefastos e desastrosos. É preciso dizer mais quando a realidade fala por si?

\section{Abstract}

In this interview, Lúcia Santaella challenges us to think about the potential of semiotics in its interfaces with communication, 
design, intelligence technologies, and also with biology, geology, geometry in an interdisciplinary perspective. She evaluates some of her main works and recognizes the link between semiotics and politics, which she has explored in a transversal way since her first books in the 1980s, establishing a dialogue with Marx and Althusser, until the most recent ones, in which she performs a semiotic reading of works by Agamben, Foucault and Negri / Hardt. Santaella also questions the current use of social networks, discusses the role of science in the face of fake news and confesses trusting that the love of knowledge and the bet on education are antidotes to the fundamentalisms that emerge in different instances of society.

\section{Keywords}

Semiotics. Science. Politics. Pragmaticism. Charles Peirce.

Recebido em 23/08/2020

Aceito em 26/08/2020 